\title{
Exploring the bio-psychosocial effects of renal replacement therapy amongst patients in a state hospital in South Africa
}

\begin{abstract}
Authors:
Bharita Harilall ${ }^{1}$

Madhubala Kasiram²

Affiliations:

${ }^{1}$ Inkosi Albert Luthuli Central Hospital, Durban,

South Africa

${ }^{2}$ School of Social Work and Community Development, University of KwaZulu-Natal, Howard College Campus, South Africa

Correspondence to: Madhubala Kasiram

Email:

kasiramm@ukzn.ac.za

Postal address:

Private Bag X54001, Durban

4000 , South Africa

Dates:

Received: 10 Sept. 2009

Accepted: 22 Nov. 2010

Published: 25 May 2011

How to cite this article:

Harilall, B. \& Kasiram,

M., 2011, 'Exploring the

bio-psychosocial effects of

renal replacement therapy amongst patients in a state hospital in South Africa',

Health SA Gesondheid

16(1), Art. \#497, 10 pages.

doi:10.4102/hsag.v16i1.497

Note:

This research was undertaken independently, without external funding.
\end{abstract}

C 2011. The Authors. Licensee: OpenJournals Publishing. This work is licensed under the Creative Commons Attribution License.
This article described a qualitative study that investigated the bio-psychosocial effects of renal replacement therapy on patients in a state hospital in South Africa. The study aimed to investigate the level of debility experienced by patients undergoing haemodialysis (HD) and continuous ambulatory peritoneal dialysis (CAPD) and to explore how this debility affects their bio-psychosocial functioning. Respondents comprised a small sample of HD and CAPD patients. Using an interview schedule as the research tool allowed rich data to be uncovered. Content analysis and reducing data into themes facilitated data analysis. Although the study was not quantitative and thus did not allow for comparative analysis, themes regarding the levels of stress emerged amongst participants. The HD group voiced greater concerns regarding the degree of debility and psychosocial distress than the CAPD group. Governmental support for holistic kidney disease treatment and careful teaming of key role players to reduce the severity and far-reaching bio-psychosocial effects of HD and CAPD treatment are recommended.

Hierdie artikel beskryf 'n kwalitatiewe studie wat die bio-psigososiale effekte van niervervangingsterapie op pasiënte in 'n staatshospitaal in Suid-Afrika ondersoek het. Die studie is gemotiveer deur die mate van debiliteit van pasiënte wat hemodialise (HD) en kontinue ambulatoriese peritoneale dialise (KAPD) ondergaan en wat oënskynlik verder strek as bloot die fisieke aspekte van die siekte en die behandeling daarvan. Respondente het bestaan uit ' $n$ klein groep HD- en KAPD-pasiënte. Deur ' $n$ onderhoudskedule as die navorsingsinstrument te gebruik, is ryk data onthul. Inhoudanalise en die redusering van data tot temas het die data-analise gefasiliteer. Alhoewel die studie nie kwantitatief was nie en vergelykende analise dus nie moontlik was nie, het temas van spanning onder die respondente voorgekom. Dit was duidelik uit die onderhoude met albei pasiëntgroepe en inhoudanalise dat die HD-groep meer bekommernis oor die graad van debiliteit en psigososiale stres getoon het as die KAPD-groep. Regeringsondersteuning vir holistiese nierbehandeling en versigtige samestelling van ' $n$ span sleutelrolspelers vir die vermindering van die erns en verreikende gevolge van HD en KAPD word voorgestel.

\section{Introduction}

To contextualise this article, it is important to explain end-stage renal disease (ESRD) first.

\section{Background}

\section{End-stage renal disease}

This is the final stage of chronic renal failure and is irreversible. During this stage the kidney has lost approximately $90 \%$ of its nephrons and the glomerular filtration rate has decreased by $80 \%$, necessitating dialysis therapy or renal transplantation (Shabalala 2004).

\section{Haemodialysis}

Haemodialysis (HD) is a treatment that removes the waste products and excess fluid that accumulate in the blood and body tissues as a result of kidney failure. The blood is filtered outside the body by means of a dialyser during two or three treatment sessions of 3-5 hours each per week (Baxter Healthcare Corporation 2006).

\section{Continuous ambulatory peritoneal dialysis}

In this form of dialysis, the patient's blood is filtered inside the body by means of a catheter in the patient's abdomen, which acts as a permanent pathway into the peritoneal cavity. Patients 
perform this dialysis at home or work, exchanging the dialysis solution in the abdomen four times per day (Mayo Clinic n.d.).

For the purposes of this article, these two types of therapy will be referred to as renal replacement therapy (RRT).

\section{International and national perspectives}

Chronic kidney disease patients experience a range of problems related to microsystemic influences resulting from the illness and the effects of the treatment regimen as well as macrosystemic influences that form a feedback loop that strain the country's resources and increase risk of kidney failure. These macrosystemic influences include poverty, HIV and/ or AIDS and poor infrastructural resources, so that resulting problems such as tuberculosis, malaria, gastroenteritis and septic abortions need management, both therapeutically and at a preventative level, to address the landscape within which renal failure thrives (Cerd et al. 2008).

Naicker (2003) qualifies that renal failure also results from diabetes and hypertension and that these need management at a primary health care level to address the burden of care at renal facilities proactively. Moosa and Kidd (2006), in fact, refer to the 'rationing' of dialysis treatment in developing countries such as South Africa and suggest that socioeconomic rather than medical factors be used as criteria for accepting patients for dialysis treatment. In response, however, Dirks and Levin (2006) caution that too few can afford private care, which itself may be unavailable because of the exodus of health professionals affecting the medical fraternity, as discussed by Moosa and Kidd (2006). Naicker (2003) shares these views, adding that dialysis treatment in developing countries depends on funding and donors and that there simply is not enough money for expensive and chronic treatments such as RRT. This context of scarce resources and illnesses that plague developing countries provides an overarching framework for the study of effects of dialysis treatment on patients. Clearly, these concerns are multilayered and need a coordinated effort to facilitate longterm redress.

\section{Dialysis options}

In South Africa, the National Health Protocol defines criteria for chronic dialysis in the public and private sectors in an attempt to establish minimum standards for renal health. However, these guidelines (South African Renal Society 2006) appear not to heed the reality of scarce human and infrastructural support resources (e.g. they do not advocate for the inclusion of a dietician and a social worker in the renal team, three-monthly reviews, etc.) and do not include measures and controls that would ensure that minimum standards are adhered to. Although the guidelines may have been drafted to promote establishment of other structures to improve renal health care rather than to further the standards in renal health, the private sector appears to be better able to accommodate the guidelines (Cerd et al. 2008; Dirks \& Levin 2006; Moosa \& Kidd 2006). The situation again emphasises that socio-economic factors dictate to whom and how renal treatment is offered in South Africa.

State facilities offer RRT in the form of HD, with CAPD being offered only to patients who are eligible for renal transplant, without constraints of gender, race or social status. Naicker (2003) reports that approximately $42 \%$ of patients on RRT in South Africa receive HD, 40\% receive CAPD and 18\% per million of the population receive kidney transplants. The more common or affordable option in state health care thus appears to be HD, although it may not necessarily be associated with fewer bio-psychosocial effects.

The ideal treatment for ESRD is the safe replacement of the patient's kidney because it reduces the dependence on dialysis therapy and allows a general improvement in well-being. However, this is not always a feasible option, leaving patients to depend on HD and CAPD despite both treatments being costly. CAPD is associated with advantages like better nutritional status, freedom of mobility, control of blood pressure and fluids and better rehabilitation (Naicker 2003; Parsoo et al. 1984). In a quantitative study Lok (1996) concluded that CAPD patients experience a higher quality of life than HD patients. However, quantitative studies do not meaningfully engage with patients to establish an in-depth understanding of how quality of life is affected by dialysis treatment (Heiwe, Clyne \& Dahlgren 2003). In addition, most of the research undertaken on the renal population has been done by medical or para-medical personnel, with little having been written about the nephrology social worker, whose primary goal is to assist patients and their families in making the social and psychological adjustments necessary to cope with both a chronic illness and the prescribed treatment regimen. In this regard, the social worker provides supportive counselling and education about the psychological impact of the illness and its various treatment options. Hence, findings from this study may contribute to knowledge in nephrology social work practice.

\section{Challenges associated with treatment options in South Africa}

The first author witnessed at first hand some of the debilitating effects of RRT on patients at a state hospital in KwaZulu-Natal, South Africa. The need is not only for psychosocial support but also for more rigorous and systematic investigation of the nature of problems experienced by patients receiving RRT at the hospital was evident. Callahan (1998) established the significance of the nephrology social worker more than a decade ago. Indeed, local guidelines (South African Renal Society 2006) clearly recognise the complex ramifications of having a chronic illness and being exposed to constant treatment and advocate the use of a team approach (including a social worker) to provide the necessary support. Shabalala (2004) has also recommended that qualitative research be undertaken to establish the multiplicity of factors and challenges faced by the dialysis population in South Africa.

The study reported here was conducted at a state hospital because a variety of microsystemic and macrosystemic 
challenges related to RRT are acutely experienced in such settings, as discussed by Moosa and Kidd (2006) and Naicker (2003). White and Grenyer (1999) warn that these challenges contribute to poor adherence to therapy, which in itself appears to be afforded to a select few. Knowledge of the ways in which patients experience their disease and treatment options is important to address some of the microsystemic challenges faced by patients whilst respecting the macrosystemic structural deficits in health care in developing countries.

\section{Theoretical approach}

Both bio-psychosocial and ecological theories informed the theoretical grounding for the study.

Bio-psychosocial theory allowed investigation into the effect of ESRD and treatment modalities on patients' physical, psychological and social worlds. Human beings are complex and simultaneously perform multiple functions that can be classified as biological or physical, psychological or mental, and social. The patient is viewed as a whole being: a biopsychosocial person made up of these intersecting spheres and functions (Schlebusch 1990). These three spheres and functions were used to guide the range of themes and questions that were explored in the interviews.

Ecological theory allowed exploration of the wide circle of systemic influences across and within the microsystem (the individual and family), mesosystem (e.g. wider group of friends and neighbours), exosystem (e.g. societal support structures) and macrosystem (state structures such as policy) that affect the patient. Ecological theory includes the larger macrosystemic sphere of influence (absent from the biopsychosocial framework), which was important in this study as it has been noted that patients at state hospitals are exposed to economic pressures. This societal influence could be explored using the ecological frame of reference and was represented in the theme pertaining to patients' economic status and stressors of unemployment. It should further be noted that these systemic influences converge similarly to the components of the bio-psychosocial model. Isolating range and intensity of specific influences was therefore neither feasible nor desirable. Indeed, it is important to note that the levels or spheres encompassed by the two theories often had several simultaneous influences that jointly added to ESRD patients' frustration.

\section{Objectives}

The study aimed to explore the bio-psychosocial functioning of patients with ESRD who received HD and/or CAPD through the following objectives:

- identifying patients' physiological, psychological and social functioning and stresses whilst undergoing HD and/or CAPD

- exploring patients' perspectives on what facilitates and challenges the treatment process

- identifying service gaps relating to bio-psychosocial stresses due to ESRD and suggesting recommendations to address these gaps.

\section{Research method and design Research paradigm and design}

This study was qualitative in nature as it sought to explore and interpret the meanings and effects of specific phenomena. In this study, patients' experiences of renal treatment and the associated meanings were explored. A combination of exploratory and descriptive research designs within the qualitative research paradigm was deemed suitable.

The study used an exploratory research design based on the recommendation of De Vos, Strydom and Fouché (2002) that exploratory research is conducted to gain insight into a situation, a phenomenon, a community or an individual. This study focused on RRT options in ESRD as perceived by the patients. It explored phenomena without any manipulation or control of human behaviour. Hence, the researchers were able to obtain greater insight into patients' knowledge and views of RRT. Owing to limited recent literature regarding patients' experiences of ESRD in South Africa being available, an exploratory design was used to gain new insight. Babbie and Mouton (2001) point out that the less developed an area, the more likely an exploratory design would be used for building a foundation of general ideas and tentative theories, as was the case in the present study.

De Vos et al. (2002) indicate that descriptive and exploratory research may merge in practice; descriptive research presents a picture of the specific details of a situation, whereas exploratory studies aim to become conversant with basic facts and create a general picture of conditions. The researchers were able to do both, as the limited number of qualitative studies on patient experiences allowed for exploratory research, whilst patients' accounts of their experiences added to the richness of the study's descriptive nature.

\section{Research instrument}

The primary research instrument was an interview schedule that contained themes for exploration (De Vos et al. 2002) derived from a thorough literature review of the biopsychosocial and ecological theoretical models. Themes for exploration thus used the broad categories of the physical, psychological, social and socio-economic worlds of patients. Probing each theme according to patients' level of comprehension enabled them to share in detail and give extended personal accounts of their views and experiences of HD and CAPD, allowing the researchers to understand their perceptions and experiences.

The interview allowed for flexibility (Brink 2006), which was particularly useful because some patients were slow to respond, owing to either short-term or long-term effects of treatment.

\section{Location}

The state hospital where the first author was employed was chosen as the location because of personal experience of the frustration RRT patients expressed and the need for 
a more systematic understanding of their experiences. Personal experience as motivation for research is discussed as an early indicator of topic and location selection by Struwig and Stead (2001). The location choice is further supported by the observation that patients who receive treatment at state facilities are likely to experience more acute frustrations related to their treatment and limited psychosocial support, as noted earlier. Further, owing to bureaucratic administration policies in state hospitals, it was deemed expedient to conduct the study in a hospital where one of the authors had a relationship with and knowledge of gate-keeping personnel and processes to obtain permission for the study and access to patients. This choice may have influenced results despite the research purpose having been carefully explained to respondents.

\section{Sample}

As this was an exploratory, descriptive study, nonprobability sampling was used (Babbie \& Mouton 2001; De Vos et al. 2002). The sample was purposive and available, and selection was based on various criteria considered necessary in furthering the purposes of the study. Firstly, respondents had to have been participating in the renal programme for at least 4 months and were selected from hospital records dating back to 2005, so that with recent but substantial experience they would meaningfully contribute to the study. Secondly, they needed to be between the ages of 18 and 60 years, so that issues pertaining to marital and other relationships and economic disempowerment, both of which are generally applicable to this age group, could be explored. Work-related frustrations would not have been able to be explored fully with respondents older than 60 years. Thirdly, they needed to be able to communicate in English so that the primary researcher (who was English speaking) would not lose information through translation. The nuances of language are important to consider during data analysis in a study aimed at gleaning rich data. Because this was a qualitative study, it was important to gain content and context-rich data through first-hand communication with patients. Finally, it was considered important that respondents were not to have had a previous kidney transplant as quality of life is superior in such patients (Dirks \& Levin 2006) and they were not likely to use state hospitals.

Sample selection commenced by examining hospital records of patients who had been attending the hospital since 2005. All potential respondents were then approached telephonically and/or personally for participation. The final sample of 15 patients was thus based on availability. Seven respondents were HD patients whilst eight received CAPD treatment.

\section{Data analysis}

Inductive rather than deductive analysis techniques were employed, specifically in identifying patterns, themes and categories that emerged from the data. Marlow (1998:213) calls this data analysis 'constructing categories' by making sense of and categorising the meaning and content of data.
Further, content analysis was employed at the levels of manifest content, which is the visible, surface content that participants openly stated, and latent content, which refers to the underlying meaning (Babbie \& Mouton 2001). In this study underlying meaning related to peripheral influences or frustrations experienced as a result of of renal treatment. After information had been transcribed to written form, it was coded according to themes (Neuman 1997) to reduce the data to a manageable format. Coding progressed according to the three phases suggested by Neuman (1997):

- open coding to analyse all data and search for themes by means of surface content analysis

- axial coding using latent content analysis to analyse raw data in relation to specified themes to identify links with literature pertaining to the renal treatment process

- selective coding to promote further abstraction relating to the emerged themes and allow comparison with data that illustrated these themes within a bio-psychosocial theoretical framework.

\section{The research process}

Once a list of prospective participants that satisfied the qualifying criteria had been compiled, patients were invited to participate in the study. An appointment was made for each. The interviews were recorded with participants' permission.

\section{Ethical considerations}

Ethical clearance was granted by both the hospital at which the study was conducted and the University of KwaZulu-Natal, under whose auspices it was conducted. Informed consent, confidentiality and anonymity were carefully addressed. Assurance of no harm was addressed by scheduling appointments for the interview such that participants would not be unduly tired (in view of them receiving treatment) and if signs of fatigue were noted, participants were given the option to complete the interview at another time. Further, when painful or difficult issues emerged, the primary researcher offered her services or referred the patient for ongoing assistance.

A study of this nature may also raise patients' expectations for improvement in services and to this end, the researcher was careful to explain the purpose of the study. Engagement and disengagement techniques were also respected, using social work skills. Patients were also offered ongoing services or referral for further services where applicable and appropriate.

\section{Trustworthiness}

Because this was a qualitative study, trustworthiness of the data had to be ensured through the dimensions of credibility, transferability, dependability and confirmability (De Vos et al. 2002).

To ensure credibility of the data, opinions of ESRD experts and a thorough literature search guided the drafting of the 
themes for exploration so that applicable matters would be investigated (De Vos et al. 2002). Furthermore, the study was conducted with honesty and integrity and the contexts and special needs of participants (such as for rest and assurance) were respected throughout. This was possible owing to the primary researcher being a medical social worker, trained in meeting psychosocial needs of patients.

A careful literature review that guided the construction of the interview schedule and sensitive, honest engagement with participants also contributed towards the consistency and dependability of the study to some extent, although replication in qualitative research is less important than gleaning context-rich and content-specific data. Confirmability of the data was checked through ensuring objectivity and deliberate use of 'neutrality'during interviews, as recommended by Milan Family Therapy. The biases and personal views of the researcher were thus adequately controlled for (Lincoln \& Guba 1985) and using social work and family therapy interviewing skills allowed the voice of the patients to dominate research results.

\section{Results and discussion}

The structure and framework used to present and discuss results are based on the theoretical grounding used in this study (Bak 2003; Vithal \& Jansen 1997). Hence, the headings cohere with the theory frames, using the physical, psychological and social stresses and effects from the biopsychosocial models and the heading 'socio-economic effects' from the ecological model. In relation to the objectives of the study, it made sense to present these results as effects followed by patient views on supportive structures considered necessary for optimal treatment (the second objective of this study). These two issues are discussed alongside each other to avoid repeating each theme and for ease of reading. The perceived gaps in social work and support services (the third objective of the study) are subsequently presented and discussed critically.

Results and their discussion are presented together to accommodate critical engagement with the literature and prevent undue repetition. This presentation style is often adopted in social work research reports. In this section, the exact responses of participants are often cited to promote rich description.

\section{Physical stresses and effects}

Most participants were affected by debilitating physical effects from both treatment modalities. Both HD and CAPD patients felt that their general energy levels and endurance were greatly reduced, which negatively affected their outlook on the treatment as promoting their holistic health and well-being.

Fatigue, headaches, pains, nausea, cramps, weight loss and loss of sight were cited as problems by HD patients, with fatigue a major concern that seriously affected their performing simple daily activities. Some of the HD patients expressed these sentiments and the associated helplessness as follows:

'I feel very tired ... sometimes nauseous ... and you can't concentrate
on what you are doing.'
'It's a kind of tiredness [where] you can't [even] read; you're too tired
to talk or to do anything ... you can't manage.'
'He [spouse] helps to give me a bath, he cleans up the house and does
the cooking.'

(HD patients)

CAPD patients also complained of tiredness, but said that relative to before their treatment they now had 'a lot of energy and felt stronger'. They did, however, complain of weight gain, sores in the mouth and general itching as other physical annoyances.

According to the dominant discourse of Polaschek (2003), dialysis is effective in generally removing the symptoms of ESRD. However, the results of this study showed that all patients generally suffered physical effects such as fatigue, which is similar to Lok's (1996) findings. The physical debility associated with the respective treatment modalities clearly affected holistic health and well-being, be it from sores or general fatigue. This systemic effect is to be expected, since the various spheres and systems are interrelated and will affect general functioning, whether positively or negatively (Kasiram 2009). This is an important consideration in providing support services.

\section{Psychological stresses and effects}

Given the degree of debility cited earlier, RRT predictably also affected participants' psychological functioning and well-being. HD patients complained of sadness, helplessness, depression and feeling like a victim, asking 'Why me?'

The reasons for HD patients' depression varied, which clearly demonstrates the role that the uniqueness of each individual's context and situation plays in influencing the experience of illness. A patient faced with the burden of disease experiences not only physical pain but also psychological, social, financial and spiritual pain, in accord with the bio-psychosocial model.

The severity of side-effects such as tiredness, loss of sight and discomfort during the dialysis procedure had a profound emotional impact on one HD patient. He was consequently unable to fulfill his role as father, husband and pastor, which exacerbated feelings of helplessness and hopelessness:

'I no longer drive because of my sight... I cannot read anymore and it's actually handicapping the work that I do as a pastor. [The] majority of the time frustration builds ... you get frustrated with the family, you get frustrated with the people [who] are assisting you ... you are always depressed, always.'

(HD patient)

Such frustration can become all consuming, with this participant clearly also demonstrating that he may be clinically depressed. His identity is closely tied to being disempowered by his illness, suggesting the need for an 
alternative, more empowered story of self and identity (White 2007).

This observation demonstrates the intersection of systemic circles of influence across the physical and psychological. These findings are consistent with an observation by White and Grenyer (1999) that anger, depression and hopelessness are commonly reported amongst HD patients.

HD patients suffered great mental anguish, fear and uncertainty about continued living:

'With HD you really don't know what's going to happen the next day. Today you can be fine, you can be laughing, and the next minute you can just fall down and die. I guess that's my main fear, of dying ...'

(HD patient)

Such uncertainty is disconcerting, adding to feelings of helplessness and hopelessness, which, if left unattended, may promote mental health breakdown (Jennette et al. 2009).

HD respondents also expressed anger, sadness and an inability to face up to the limitations imposed by their disease. Many sought solace in spirituality, as noted by authors such as Kasiram (2006a, 2006b) and Den Hollander (2006).

Although CAPD patients also experienced a degree of mental anguish, some again expressed gratitude at the CAPD treatment regimen offering them more mobility and less constraint than what was possible before the commencement of the treatment:

'I do not have a problem with the bag treatment... I feel alive, good. Ever since I have been on the bag I have been a normal person, active and with my work situation it makes me go forward.'

(CAPD patient)

Although the study did not aim to compare the level of mental anguish experienced by the two treatment groups, but rather provided a description of their respective experiences, the CAPD group clearly experienced less mental anguish.

Both groups also feared the prospect of infections and death, which exacerbated their anxiety and depression. They were anxious about continuity of life depending on external variables over which they had no control, such as high technology medicine. Also, the possibility of hospital worker strikes and power cuts that would prevent services from being properly accessed creates very real fears amongst patients (SABC 2010), with negative repercussions for kidney patients who have to receive regular treatment. These concerns straddle patients' physical, psychological and socioeconomic spheres (using the bio-psychosocial and ecological perspectives).

The chronic nature of the illness and its treatment called for overwhelming and stressful long-term health and lifestyle adjustments in both patient groups, which affected them psychologically. HD patients, however, again voiced greater concern, as supported by findings of Lok (1996).
A possible explanation for the CAPD patients not complaining extensively about lifestyle adjustments may be that CAPD allows a more flexible diet. One CAPD patient, who had previous experience of HD, said:

'Yes, there is a big difference, the experience on HD limited one to certain diets ... on CAPD, no limitations ... [you] can eat whatever you like ... this is a positive aspect towards managing CAPD more comfortably.'

(CAPD patient)

Diet is generally difficult to control, with Herselman (2008) confirming that attempts to convince patients with medical arguments, do not produce desired outcomes. Tsay (cited in Shabalala 2004) too reports that many ESRD patients find it difficult to comply with fluid restrictions and need to make major lifestyle changes and exhibit self-control. Both treatment groups may benefit from support by a multidisciplinary professional team (e.g. including a dietician and a medical or nephrology social worker) to promote adherence to a diet plan through creative and meaningful engagement with both the patient and their family to ensure optimum nutrition (Callahan 1998).

Physical bodily changes and perceived physical unattractiveness resulting from long-term HD and CAPD treatment were also stressful for participants and their partners, affecting their self-concept and relationships. Participant discomfort is evident from the following responses:

'I was conscious ... [of] walking and people looking at [me] and every day you [have] a different excuse. I tell them I don't know why I'm swelling up ... I felt ashamed of the sickness ...'

(CAPD patient)

'My appearance changed drastically ... as time has gone the stomach has gone bigger and bigger and everyone thinks I'm pregnant ... you have to go for loose, elasticated dresses. My manager wasn't happy to have the likes of my appearance in the front office.'

(HD patient)

Edwards et al. (2005) agree that body image problems can contribute to stress in chronically diseased patients, whilst Kasiram et al. (2010) also highlight how body image influences self-esteem.

Such responses also provide evidence of physical repercussions that give rise to psychological and social distress, as illustrated in the ecological paradigm where concentric circles of influence blur along their lines of influence. The bio-psychosocial model also explains the reciprocity between the biological and the psychosocial dimensions.

Some positive effects were, however, also mentioned. CAPD participants in particular reported hope and renewed appreciation of life, having previously experienced the difficult HD treatment regimen. This observation qualitatively highlights the general findings of Lok (1996) that CAPD patients enjoy a better quality of life. These participants believed they had been offered a second chance and looked forward to the future. Experiencing some positive 
effects as a result of their treatment seemed to influence their general sense of well-being. HD patients, however, did not report similar positive experiences, presumably because of high levels of frustration imposed by the physical effects of their treatment.

\section{Social stresses and effects}

All participants found it difficult to integrate the requirements of the dialysis regimen into daily schedules, which affected their social lives, especially with regard to sports and holidays:

'I used to play a lot of volleyball ... it is very difficult as now you don't have the energy ... [you] can't go on holidays [because of] the dialysis schedule ...

(HD patient)

'I used to play for a soccer team ... it makes me feel very bad, hurts inside that I can't play soccer anymore ... if I try to run a little bit, I get tired ... so it makes me feel really bad inside.'

(CAPD patient)

Similar effects have also been discussed by Polaschek (2003).

Two CAPD participants indicated that they had changed their interests by taking up new sports and hobbies and so integrated the treatment regimen into their lifestyle:

'I was playing soccer, was an athlete as well ... I now read, go fishing.'

(CAPD patient)

That some participants could make this shift indicates that flexibility may be key to better patient management and points to gaps for health advisors and social workers to offer support services.

Generally, relationships with partners were not cited as being strained because of the illness and its treatment by either the HD or the CAPD group. Respondents indicated that their relationships were healthy prior to the onset of treatment and continued so during treatment, with compassion and care characterising the relationship:

'He [husband] ... takes good care of me, there are days that I feel very sick; [if] I can't [take] a bath, he helps me to give me a bath. He cleans up the house; he does everything for me.'

(HD patient)

Another respondent said:

'He [husband] always tells me that he does not want to hurt me and feels sorry for me ... he is a man with compassion ...'

(HD patient)

However, both HD and CAPD respondents complained that intimacy and sexual relations were affected by poor body image, feelings of lack of desirability and fatigue. One HD patient lamented how his spouse viewed him now and was doubtful of her sense of fulfillment in their marriage. Associated with remorse was a sense of guilt at being responsible for their changed sexual relationship:

'The truth is that I'm not sure whether dialysis people can be sexually intimate. But I realised that ever since I [have been] on HD it has affected us very, very badly. We have discussed it, my wife and I. It affects me ... it's really causing concerns because I can't really explain it but it's more [a case] of impotence.'

(HD patient)
Clearly, this is a grave concern, contradicting the earlier result about there being limited strain on spousal relationships. Presumably, in the earlier result, if the relationship was not threatened with breakdown, it was still perceived as acceptable, in that supportive assistance from the partner for the treatment remained unaffected. This may mean that the illness and its treatment occupies a central position in the life of an ESRD patient, with them not perceiving themselves as sexual beings with sexual needs.

Compassion appeared to be more important than a sexual relationship for some patients, pointing to an opportunity for support services to engage meaningfully with patient sexuality. These findings are in line with those from a recent study by Burnett et al. (2009) where sexual talk was found to be avoided and initiated by only half the patients in their sample. Locally, South African patients are generally regarded as being less confident in communicating with medical staff, especially when they come from disadvantaged backgrounds and receive treatment at state hospitals.

Patients complained that their roles and responsibilities relating to parenting were affected as medical care governed their time:

'I was the head of the house ... I was the person [who] provided the food, [paid] the bills ... now I'm inactive ... my son was staying out ... when he found out I was very ill ... he moved in and has taken on most of the responsibilities and it concerns me ...'

(HD patient)

This finding has serious implications for self-image and confidence and possibly strains family relationships, as suggested by family therapy theory and ecological theory and which has also been highlighted by Thabane (2008).

White and Grenyer (1999) confirm that ESRD is indeed a progressive, debilitating chronic illness that requires constant adaptations and that family and most other relationships that existed prior to the illness are progressively changed by the presence and the responsibility of caring for a dialysis patient.

Respondents found relinquishing responsibilities challenging, sometimes even necessitating supportive professional assistance. The burden of care placed on caregivers and/or family members who need to assume multiple roles needs attention, as burnout and compassion fatigue is likely to affect the quality of care (Kasiram \& Khosa 2008; Thabane 2008).

HD as well as CAPD patients also lamented the social isolation imposed by their treatment:

'I used to play a lot of volleyball ... [it] is very difficult, as now you don't have the energy, that's the most important thing ... [you] can't go on holidays ...'

(HD patient)

'Before we used to go camping and to the beach to swim with the kids, but that does not happen anymore because I have to do my bag changes.'

(CAPD patient) 
However, some CAPD patients reported taking up alternative hobbies that were satisfying and facilitated their inclusion in family and community life. This appears to be directly related to the sense of hope and healthier living generated by the physical aspects of this treatment, suggesting that the reciprocal relationship between the physical and psychosocial aspects of RRT was 'hopeful' for CAPD patients.

\section{Socio-economic stresses and effects}

The ability to work and lead a productive life greatly affected all participants. HD participants were particularly distressed that they could no longer work and provide for their families, a finding that was earlier discussed under the social effects.

\section{A frustrated HD patient said:}

'Being a kidney patient, to find employment is absolutely difficult because nobody wants to take you because you take time off and get absent.'

(HD patient)

Shabalala (2004) agrees that unemployment is a core stressor amongst chronic ESRD patients.

Some CAPD participants, however, were able to work and remain economically productive with support from health advisors. Essentially, they were employed because they were able to integrate their CAPD regimen into their work schedules. This did, however, depend on education about kidney treatment and advocacy to respect the patient's rights with the employer. One of the CAPD patients returned to his teaching career, another was employed as a supervisor in a business and yet another was employed as a casual worker at a clothing store whilst receiving treatment.

Opportunities for support services for HD patients in particular are thus evident. A fully functional service team that includes a social worker and an occupational therapist would be helpful to examine alternative employment opportunities with patients. However, as discussed earlier, macrosystemic challenges and financial cutbacks prevent optimal service provision, particularly in developing countries and state-controlled institutions (Dirks \& Levin 2006; Moosa \& Kidd 2006; Naicker 2003).

Results also revealed that neither patient group was adequately informed about their labour rights. This suggests that an opportunity exists for social workers on the support team to advocate on patients' behalf and provide assistance during employer consultation.

\section{Coping}

This theme may be incorporated into several of the others discussed in this article, but can also stand alone as an item related to the third objective of the study. The theme emerged strongly and therefore justifies separate discussion.

Various coping mechanisms were used by participants. Psychologically, participants tended to adopt individual strategies to cope with their treatment. This involved acceptance of their medical problems and having a positive mindset in managing their condition. For some, sheer determination and endurance facilitated their psychological coping. From a bio-psychosocial perspective, such individual coping may prove frustrating since frustrations and stressors were clearly interrelated, necessitating a team approach to problem solving.

Other respondents referred to making cognitive shifts to cope. Rather than being overwhelmed by the negative aspects of the treatment, they focused on the fact that they were given another chance to live. This is supported by Cares, Buker and Owens (cited in Shabalala 2004) who found that participants who regard renal failure as a challenge rather than a life sentence, respond well to treatment; however, those who regard renal failure as punitive are bitter, angry and confused by their situation and tend to respond poorly to treatment.

HD patients, on the other hand, tended to use avoidance and displaced anger as coping strategies. Opportunities for support service are thus apparent, as all bio-psychosocial effects should be addressed alongside one another by the renal team to promote holistic health.

The nurse-patient relationship also played a significant role in mediating the effects of dialysis in both participant groups. Both CAPD and HD patients appreciated information and a compassionate and caring attitude from nurses. These findings are supported by Jennette et al. (2009) who emphasise the importance of sensitive communication during dialysis education. Kasiram and Naidoo (2006) suggest 'edutainment' as a helpful means to educate. Owing to financial constraints experienced in state medical care, this important function may well be sidelined, as highlighted by Cerd et al. (2008).

Another important coping strategy was participation in a support group, which was viewed as supportive and validating of the pain, prejudice and fear patients experienced. A group structure thus provided a context in which other patients' stories could be heard and enabled participants to re-evaluate their own situations and gain perspective. Owing to constraints discussed by Moosa and Kidd (2006), this service is not regularly available or accessible, which highlights the need to address this support service gap.

All participants valued the support and/or financial assistance received from family and their religious systems to address the concern of financial hardship. In tough economic times, the financial burden placed on the family and the guilt experienced by the patient need to be actively confronted with the help of social workers and other professional staff who may also network with volunteers to ease this burden. Structural redress of changes to the macrosystem (e.g. extending the hospital team, changes to funding policies, etc.), as discussed in the ecological theoretical model is clearly needed to manage renal disease effectively and proactively. 


\section{Limitations of the study}

The sample was selectively drawn from renal patients at a state hospital in one province of South Africa. Hence, opportunity for generalisation of findings is limited, specifically regarding the private sector, race and socioeconomic groupings (state patients are primarily from less privileged backgrounds).

The study employed a very small sample (only 15 respondents), which, although considered feasible for a qualitative study, may still be regarded as too small to draw definitive conclusions. However, it should be noted that the study was expected to serve as a springboard for further, rigorous research using both qualitative and quantitative methodologies with more representative sample groups.

The fact that only patients who could communicate in English were selected could have biased the study results, because it is expected that such patients may also be from a specific socio-economic class. However, given the need to glean context-rich data and content-rich data, this criterion has been justified in the discussion on sample details.

\section{Recommendations}

Several recommendations for addressing the identified opportunities for support services followed from the investigation:

- The bio-psychosocial effect of both treatment options need to be viewed multi-systemically. A team approach, whereby plans are tailored according to patients' needs and all possible systemic influences are considered, is important. Infrastructural support such as enforced government policy for holistic care based on a team approach should be secured, perhaps with the help of lobbying from pressure groups.

- Nephrology and/or medical social workers need to recognise and respond to the emotional impact of chronic kidney disease and its treatment. According to the ecological theory, partners, families and significant others in the community should be included in the treatment process, so that psycho-education and support would receive due attention (Jennette et al. 2009). In particular, family therapy and peer group work could offer meaningful support to prevent feelings of alienation brought on by the illness and the treatment process (Dano 2006).

- To ease the traumatic effect of treatment on the patient's role as provider and parent, liaison with employee assistance practitioner networks may be beneficial. From an ecological perspective, the exosystemic influence of business and community is important in planning a successful financial future for patients.

- Because both HD and CAPD treatment options impact sexual relations, patients should be encouraged to talk about sex frankly during the treatment process. Specialised therapeutic intervention such as sex therapy may be necessary. The implication for the medical or nephrology social worker is to invite open discussion of sexual matters, as appropriate.

- Physical fatigue and functional capacity, found to be a source of great stress, may be addressed by nurses, physiotherapists, occupational therapists and dieticians. A multidisciplinary team of professionals should be recognised as inherent and necessary to holistic treatment and care.

- Future research could include quantitative studies to establish relationships across variables with larger samples covering more hospitals. Comparison of variables such as treatment option (HD versus CAPD), location (state versus private hospitals) and patient profile (rural versus urban) may also be valuable.

\section{Conclusion}

Both HD and CAPD treatment were found to pose many biopsychosocial challenges.

The main physical effect was cited as fatigue, which influenced functional capacity. HD respondents were seriously affected because they perceived their treatment as constraining. Long-term dialysis increased patient dependence, reduced work capacity, brought on family role reversal and strained sexual relations.

Vulnerability, uncertainty, fear and depression were cited as psychological effects. HD participants demonstrated strong emotional reactions to dialysis including anger, sadness and an inability to face up to the limitations imposed by their disease. Both HD and CAPD respondents were anxious about possible complications and infections and feared an untimely death.

Both the HD and the CAPD patients reported solid marital and partner relationships. These relationships appeared to be functioning optimally prior to the onset of treatment and hence such experiences did not lead to marital breakdown or disintegration of relationships. However, sexual intimacy was strained by the illness and its treatment.

HD patients experienced great financial burden as the demands of the treatment regimen were exacting and did not allow for decent employment. CAPD respondents, however, were able to engage in some form of productive employment.

Treatment success was perceived to be facilitated by personal coping mechanisms, faith, family support, a compassionate service team, proper education, monitoring and group therapy.

\section{References}

Babbie, E. \& Mouton, J., 2001, The practice of social research, Oxford University Press, Cape Town.

Bak, N., 2003, Completing your thesis: A practical guide, Van Schaik, Cape Town.

Baxter Healthcare Corporation, 2006, Understanding treatment options for renal therapy, pamphlet obtained from the Renal Unit at Albert Luthuli Hospital. 
Brink, H., 2006, Fundamentals of research methodology for health care professionals, Juta, Cape Town.

Burnett, J., Canter, A., Rubin, M. \& Verdirame, M., 2009, 'Let's talk about sex: understanding social workers' approaches to discussing sexuality with CKD patients', Journal of Nephrology Social Work 32, 9-14, viewed on 08 September 2010, from www.kidney.org/professionals/cnsw/JNSWonline

Callahan, M.B., 1998, 'The role of the nephrology social worker in optimizing treatment outcomes for end-stage renal disease patients', Dialysis and Transplantation 27(11), 630-642.

Cerd, J., Bagga, A., Kher, V. \& Chakravathi, R.M., 2008, 'The contrasting characteristics of acute kidney injury in developing and developed countries', Nature Reviews Nephrology 4, 138-153.

Dano, B., 2006, 'Intimacy challenges faced by married sero-discordant couples with HIV/AIDS', in M. Kasiram, R. Partab \& B. Dano (eds.), HIV/AIDS in Sub-Saharan Africa: The not so silent presence, pp. 43-54, Print Connection, Pinetown.

De Vos, A.S., Strydom, H. \& Fouché, C.B., 2002, Research at grass roots: for the social sciences and human service professions, Van Schaik, Pretoria.

Den Hollander, W., 2006, 'A training programme for church leaders working with HIV/ AIDS in South Africa', in M. Kasiram, R. Partab \& and B. Dano (eds.), HIV/AIDS in Sub-Saharan Africa: The not so silent presence, pp. 135-146, Print Connection, Pinetown.

Dirks, J.H. \& Levin, N.W., 2006, 'Dialysis rationing in South Africa: a global message', Kidney International 70, 982-984. doi:10.1038/sj.ki.5001798, PMid:16957745

Edwards, S.D., Ngcobo, H.S.B., Edwards, D.J. \& Palavar, K., 2005, 'Exploring the relationship between physical activity, psychological well-being and physical selfperception in different exercise groups', South African Journal for Research in Sport, Physical Education and Recreation 27(1), 75-90.

Heiwe, S., Clyne, N. \& Dahlgren, M.A., 2003, 'Living with chronic renal failure: patients' experiences of their physical and functional capacity', Physiotherapy Research International 8(4), 167-177. doi:10.1002/pri.287, PMid:14730721

Herselman, M., 2008, 'Non-adherence to dietary prescriptions in chronic kidney disease', South African Journal of Clinical Nutrition 21(2), 13-14.

Jennette, C., Derebail, V., Baldwin, J. \& Cameron, S., 2009, 'Renal replacement therapy and barriers to choice: Using a mixed methods approach to explore the patient's perspective', Journal of Nephrology Social Work 32, 15-26, viewed
September 2010, from www.kidney.org/professionals/cnsw/JNSWonline

Kasiram, M., 2006a, 'Towards spiritual competence in HIV/AIDS care', in M. Kasiram, R. Partab \& B. Dano (eds.), HIV/AIDS in Sub-Saharan Africa: The not so silent presence, pp. 115-134, Print Connection, Pinetown. doi:10.1177/0020872807085860

Kasiram, M., 2006b, 'Hope and healing through spirituality - a meeting of minds between social work and theology', The Social Work Practitioner/Researcher 18(2), 165-173.

Kasiram, M. \& Naidoo, P., 2006, 'Unplanned pregnancy amongst students at UKZN', Social Work 42(3/4), 341-353.

Kasiram, M. \& Khosa, V., 2008, 'Trauma counselling: beyond the individual', International Social Work 51(2), 220-232.

Kasiram, M., 2009, 'Trauma, HIV/AIDS and healing: what can a systems overview and family therapy offer?', plenary paper presented at the 17th World IFTA congress, Portoroz, Slovenia, 4-7th March.
Kasiram, M., Pais, C., Ilbury, B. \& Sookoo, A., 2010, 'Staying alive with dance! Self-care for women', Social Work Maatskaplike Werk 46(2), 224-233.

Lincoln, Y.S. \& Guba, E.G., 1985, Naturalistic enquiry, Sage, London.

Lok, P., 1996, 'Quality of life among dialysis patients', Journal of Advanced Nursing 23 873-881. doi:10.1046/j.1365-2648.1996.00893.x, PMid:8732512

Marlow, C.R., 1998, Research methods for generalist social work, Brooks/Cole, Belmont, C.A.

Mayo Clinic n.d., Chronic kidney failure, viewed on 14 March 2007, from http://www. mayoclinic.com/health/kidney-failure/DS00682/DSECTION=3

Moosa, M.R. \& Kidd, M., 2006, 'The dangers of rationing dialysis treatment: The dilemma facing a developing country', Kidney International 70, 1107-1114. doi:10.1038/sj.ki.5001750, PMid:16883316

Naicker, S., 2003, 'End-stage renal disease in sub-Saharan and South Africa', Kidney International 63 (83), S119-S122. doi:10.1046/j.1523-1755.63.s83.25.x

Neuman, W.L., 1997, Social research methods, Allyn and Bacon, Needham Heights.

Parsoo, I., Seedat, Y.K., Naicker, S. \& Kallmeyer, J.C., 1984, 'Continuous ambulatory peritoneal dialysis in South Africa - a four-year experience', Peritoneal Dialysis International 4(2), 78-81.

Polaschek, N., 2003, 'Living on dialysis: concerns of clients in a renal setting', Journa of Advanced Nursing 41(1), 44-52. doi:10.1046/j.1365-2648.2003.02504.x, PMid:12519287

SABC. See South African Broadcasting Corporation.

South African Broadcasting Corporation, 2010, News at 7, television news bulletin SABC News, Johannesburg, 08 September.

South African Renal Society, 2006, Guidelines for the optimal care of patients on chronic dialysis in South Africa, viewed on 16 February 2010, from www. kznhealth.gov.za/medicine/sars.pdf.

Schlebusch, L., 1990, Clinical health psychology: a behavioural medicine perspective, Southern Book, Halfway House.

Shabalala, T.M., 2004, 'Factors that facilitate adherence to haemodialysis therapy amongst patients with chronic renal failure', MA dissertation, Department of Nursing, University of KwaZulu-Natal.

Struwig, F.W. \& Stead, G.B., 2001, Planning, designing and reporting research, Pearson Education South Africa, Cape Town.

Thabane, B., 2008, 'Effects of women's labour on migration on the family: Perceptions of the labour migrant', MA dissertation, Department of Social Work, University of KwaZulu-Natal.

Vithal, R. \& Jansen, J., 1997, Steps in writing a research proposal, Juta, Kenwyn.

White, M., 2007, Maps of narrative practice, Norton, New York.

White, Y. \& Grenyer, B.F.S., 1999, 'The biopsychosocial impact of end-stage renal disease. The experience of dialysis patients and their partners', Journal of Advanced Nursing 30(6), 1312-1320. doi:10.1046/j.1365-2648.1999.01236. PMid:1058364 